\title{
Correction to: Linking demyelination to compound action potential dispersion with a spike-diffuse-spike approach
}

Richard Naud $^{1,2^{*}}$ and André Longtin ${ }^{2}$

The original article can be found online at https://doi.org/10.1186/ s13408-019-0071-6

${ }^{\text {*Correspondence: }}$ rnaud@uottawa.ca

'Ottawa Brain and Mind Research Institute, Department of Cellular and Molecular Medicine, University of Ottawa, Ottawa, Canada ${ }^{2}$ Department of Physics, University of Ottawa, Ottawa, Canada

\section{Springer}

Following publication of the original article [1], the authors noticed a mistake in the first paragraph within "Altered propagation":

The phrase "When an internode undergoes demyelination, its transverse resistance is assumed to increase while its capacitance decreases [29]" should read: "When an internode undergoes demyelination, its transverse resistance is assumed to decrease while its capacitance increases [29]"

Figure 1(d) has also been corrected due to an incorrect arrangement of colors:

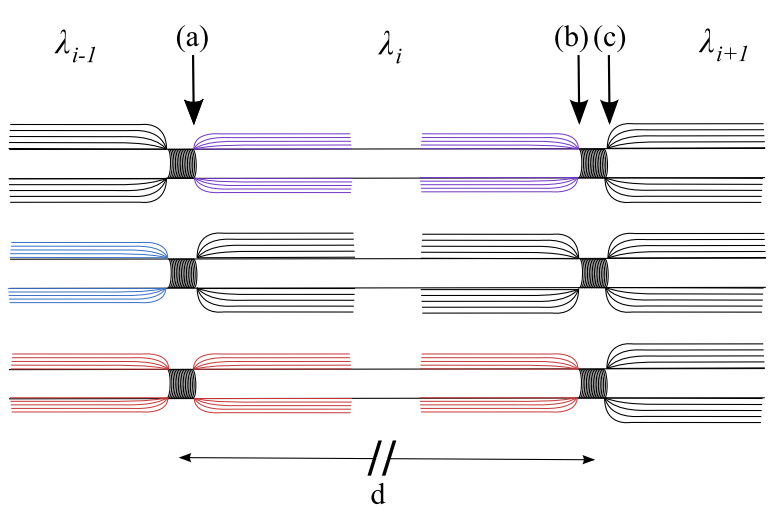

Figure 1 The Stochastic Spike-Diffuse-Spike Model. (d) Schematic illustration of two Ranvier nodes separated by a distance $d$ for the three damage configurations. For a propagation from left to right, we consider three possibilities for an action potential starting at node (a). Top: demyelination of orthodromic internode. Middle: demyelination of antidromic internode. Bottom: equal demyelination of both anti- and orthodromic internodes

\section{Publisher's Note}

Springer Nature remains neutral with regard to jurisdictional claims in published maps and institutional affiliations.

Published online: 20 April 2020

\section{References}

1. Naud R, Longtin A. Linking demyelination to compound action potential dispersion with a spike-diffuse-spike approach. J Math Neurosci. 2019;9:3. https://doi.org/10.1186/s13408-019-0071-6.

(c) The Author(s) 2020. This article is licensed under a Creative Commons Attribution 4.0 International License, which permits use, sharing, adaptation, distribution and reproduction in any medium or format, as long as you give appropriate credit to the original author(s) and the source, provide a link to the Creative Commons licence, and indicate if changes were made. The images or other third party material in this article are included in the article's Creative Commons licence, unless indicated otherwise in a credit line to the material. If material is not included in the article's Creative Commons licence and your intended use is not permitted by statutory regulation or exceeds the permitted use, you will need to obtain permission directly from the copyright holder. To view a copy of this licence, visit http://creativecommons.org/licenses/by/4.0/. 